\title{
Natural Products as Lead Compounds for Sodium Glucose Cotransporter (SGLT) Inhibitors
}

Author
Wolfgang Blaschek

Affiliation
Formerly: Institute of Pharmacy, Department of Pharmaceu-
tical Biology, Christian-Albrechts-University of Kiel, Kiel,
Germany

Key words

Malus domestica, Rosaceae, Phlorizin, flavonoids, SGLT-inhibitors, gliflozins, diabetes

received February 9, 2017

revised March 3, 2017

accepted March 6, 2017

Bibliography

DOI http://dx.doi.org/10.1055/s-0043-106050

Published online April 10, 2017 | Planta Med 2017; 83: 985-

993 @ Georg Thieme Verlag KG Stuttgart · New York I

ISSN 0032-0943

Correspondence

Prof. Dr. Wolfgang Blaschek

Vogteiweg 13 B, 24119 Kronshagen, Germany

Phone: + 49431583498

wbla@pharmazie.uni-kiel.de

\begin{abstract}
Glucose homeostasis is maintained by antagonistic hormones such as insulin and glucagon as well as by regulation of glucose absorption, gluconeogenesis, biosynthesis and mobilization of glycogen, glucose consumption in all tissues and glomerular filtration, and reabsorption of glucose in the kidneys. Glucose enters or leaves cells mainly with the help of two membrane integrated transporters belonging either to the family of facilitative glucose transporters (GLUTS) or to the family of sodium glucose cotransporters (SGLTS). The intestinal glucose absorption by endothelial cells is managed by SGLT1, the transfer from them to the blood by GLUT2. In the kidney SGLT2 and SGLT1 are responsible for reabsorption of filtered glucose from the primary urine, and GLUT2 and GLUT1 enable the transport of glucose from epithelial cells back into the blood stream.

The flavonoid phlorizin was isolated from the bark of apple trees and shown to cause glucosuria. Phlorizin is an inhibitor of SGLT1 and SGLT2. With phlorizin as lead compound, specific inhibitors of SGLT2 were developed in the last decade and some of them have been approved for treatment mainly of type 2 diabetes. Inhibition of SGLT2 eliminates excess glucose via the urine. In recent times, the dual SGLT1/SGLT2 inhibitory activity of phlorizin has served as a model for the development and testing of new drugs exhibiting both activities. Besides phlorizin, also some other flavonoids and especially flavonoid enriched plant extracts have been investigated for their potency to reduce postprandial blood glucose levels which can be helpful in the prevention and supplementary treatment especially of type 2 diabetes.
\end{abstract}

\section{The History of Phlorizin}

In 1835 a bitter tasting compound was isolated from the bark of apple trees and named phloridzin (later most commonly called phlorizin, but also phlorrhizin, phlorhizin, or phlorizoside) [1]. The name phloridzin (in Greek: $\varphi \lambda$ oıó $\varsigma$ = bark, $\rho i \zeta \alpha=$ root) was chosen as higher concentrations of the compound were found in the root bark compared to the stem bark. More than 100 years later, in 1942, the complete structure of phlorizin was determined by total synthesis [2]. Phlorizin was shown to be a flavonoid, more precisely the 2 '-glucoside of phloretin, a dihydrochalcone (chemical name: 1-[2-( $\beta$-D-glucopyranosyloxy)-4,6-dihydroxyphenyl]-3(4-hydroxyphenyl)-1-propanone; $>$ Fig. 1). Due to their bitter flavor, the phlorizin containing extracts of the bark of apple trees re- minded of extracts of the bark from cinchona and willow trees, and originally were thought to have antipyretic properties and might be used in the treatment of fevers and infectious diseases, especially malaria [3]. Then, in 1886, it was described that phlorizin given in high doses of more than $1.0 \mathrm{~g}$ causes glucosuria in humans [4]. At these days, diabetes mellitus also causing glucosuria was considered to be a structural disease of the kidneys. Later on, by further studies with phlorizin, it was concluded that glycosuria, polyuria, and weight loss caused by phlorizin in animals is the equivalent to human diabetes and phlorizin became one of the main instruments to study this human disorder and the function of the kidneys [5]. By intravenous administration of phlorizin to healthy people, the measurement of the glomerular filtration rate for glucose in the kidney became possible in the 1930s [6]. Some decades later, it could be shown that intestinal glucose ab- 
sorption is done by sodium-glucose cotransport [7] and that phlorizin inhibits the transport of glucose in the small intestine [8]. Then it was described that the renal reabsorption of glucose in the kidney is located in the luminal membrane of brush border cells of the proximal part of the tubulus [9]. Finally, investigations on the inhibition of sugar transport across membranes with the help of phlorizin led to the identification of the coupled sodiumglucose transport mechanism [10]. The detailed characterization of the so-called sodium glucose cotransporters (SGLTs) followed [11] and their potential inhibition became more and more interesting for the treatment of diabetes.

Phlorizin could be shown to be a potent inhibitor of both known SGLTs for glucose transport: the intestinal SGLT-1 responsible for the absorption of glucose from the small intestine, and SGLT-2 and SGLT-1 responsible together for the reabsorption of glucose from the primary urine in the kidney. Phlorizin, however, had some disadvantages for the use in therapy of diabetes. Phlorizin inhibits both SGLTs with low therapeutic selectivity, it is poorly absorbed in the small intestine, and it is effectively hydrolyzed by intestinal lactase (LPH = lactose-phlorizin-hydrolase) resulting in low oral bioavailability and the aglycon phloretin as hydrolysis product is an inhibitor of the ubiquitous glucose transporter GLUT1 obstructing glucose uptake into various tissues [12]. Nevertheless, phlorizin was and is the lead compound for the development of synthetic analogs with improved bioavailability, stability, and selectivity for SGLT2 and investigations on the use of phlorizin, including food products for an additional treatment of diabetes and obesity, again are of interest. First some Oglucoside analogs of phlorizin were synthesized and tested. The orally available STLT-2-inhibitor T-1095 ( $\triangleright$ Fig. 1) developed at the end of the last century had a better selectivity for SGLT- 2 with an $\mathrm{IC}_{50}$ of $200 \mathrm{nM}$ against SGLT- 1 and $50 \mathrm{nM}$ against SGLT-2 [13]. Other O-glucoside analogs developed later, in the first decade of this century, were sergliflozin [14] or remogliflozin [15] ( Fig. 1). The disadvantages of all these O-glucoside analogs of phlorizin still were a poor pharmacokinetic stability and an insufficient selectivity for SGLT2. A method for the synthesis of C-glycoside analogs of phlorizin was first described in 2000 [16] and some years later, in 2008, the discovery of dapagliflozin ( Fig. 1), a C-glycoside analog with high SGLT2 selectivity, was published [17]. Dapagliflozin was approved for the treatment of diabetes type 2 in Europe in 2012 and in the USA in 2014. Development, approval, and marketing of other C-glycoside analogs of phlorizin like canagliflozin ( Fig. 1; approval EU/USA in 2013) [18] and empagliflozin ( $\bullet$ Fig. 1; approval EU/USA in 2014) [19] with a high SGLT2-selectivity for the treatment of diabetes type 2 followed in the last years and intensive research in this field is going on. Other gliflozins like ipragliflozin, luseogliflozin, and tofogliflozin have been approved in Japan [20] and the research for new gliflozins is going on. Nowadays, also the interest in combined SGLT2/SGLT1-inhibitors is growing continuously. Compounds such as sotagliflozin ( $\vee$ Fig. 1) are thought to be applied also together with insulin in therapy of type 1 diabetes [21].

In the following, some aspects of this historical outline will be discussed more in detail. In this context, also some readable reviews published in the last few years should be mentioned [20, 22-25].

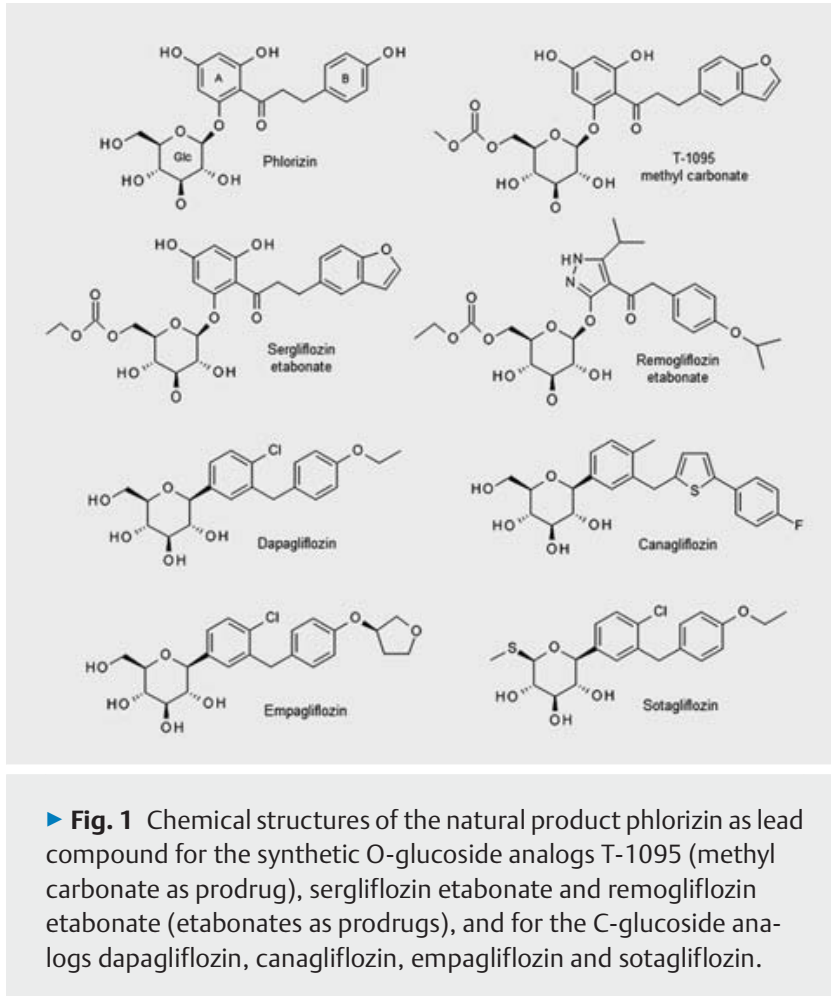

\section{Diabetes mellitus: Disease, Epidemiology, Diagnosis and Medications}

Diabetes mellitus (DM), shortly named diabetes, is a serious, chronic, metabolic disease with high blood sugar levels over a prolonged period of time. Hyperglycemia results from inadequate insulin secretion, insulin resistance, or excessive glucagon secretion. Typical first symptoms of diabetes are frequent urination and increased thirst. Long term problems of diabetes mainly result from damages in small blood vessels and include cardiovascular diseases such as stroke and heart attack, chronic kidney failure (diabetic nephropathy), peripheral neuropathy, and vascular diseases like foot ulcers and eye damage (diabetic retinopathy). Three main types of diabetes are known [26, 27]:

Type 1 diabetes mellitus (T1DM) is caused by insufficient up to no more production of insulin in the beta cells of the islets of Langerhans in the pancreas due to a T-cell-mediated autoimmune attack against beta cells, and consequently it is an immune-mediated disease. Therefore, most cases of T1DM are seen in children and young people (insulin dependent diabetes).

Type 2 diabetes mellitus (T2DM) begins with a decreased respond of the cells of many body-tissues to insulin (insulin resistance), resulting in a permanent increase in insulin production by pancreatic beta cells until their exhaustion. Finally also a lack of insulin is developing. T2DM is rather characteristic for adult and obese people and often develops gradually.

Gestational diabetes can develop in pregnant women (incidence $2-10 \%$ ) without previous high blood sugar levels. Concerning an insufficient responsiveness of body cells to insulin and an inadequate insulin secretion, gestational diabetes resembles 
T2DM. Gestational diabetes often disappears (about 95\% of women) after pregnancy.

In addition to these main categories, some other specific individual types of diabetes are described and combinations of different forms of diabetes can also occur.

According to the 2016 report of the World Health Organization (WHO), the worldwide rates increased from 108 million people with diabetes in the year 1980 to 422 million people in 2014 [28]. About $90 \%$ of all cases of diabetes are T2DM. Greatest increases in rates of T2DM have been seen in developing low- and middle-income countries and are caused by a combination of various factors like sedentary lifestyles due to urbanization, less physically demanding work, increased intake of foods with high energy density (sugar, fats), and the resulting development of excessive body weight [28].

Short term and long term glucose levels in blood can be determined (for reviews see $[26,27]$. Normal fasting blood glucose levels after a fasting period of 8 hours are $70-110 \mathrm{mg} / \mathrm{dL}$. Two-hour postprandial glucose levels should be $<140 \mathrm{mg} / \mathrm{dL}$. In an oral glucose tolerance test (OGTT) after receiving $75 \mathrm{~g}$ of glucose, the two-hour glucose level should be below $200 \mathrm{mg} / \mathrm{dL}$. The A1C test (also called hemoglobin A1c, HbA1c, or glycohemoglobin test) is based on the non-enzymatic attachment of blood glucose to hemoglobin A located in red blood cells. The higher the blood glucose level over a longer period of time, the higher the amount of glycated hemoglobin. As erythrocytes typically have a live time of about 90-120 days, the test reflects the average level of blood glucose for the past 3 months. The normal range for the hemoglobin A1c level is $4-5.7 \%$ of total hemoglobin. Hemoglobin A1c levels of $5.7-6.4 \%$ are signs for prediabetes and levels of $>6.5 \%$ indicate diabetes. Good diabetic control is considered when readings for $\mathrm{HbA} 1 \mathrm{c}$ are below $7 \%$.

Medication of diabetes includes insulins and different classes of oral medications. Combinations of various medications are used often but not described here. In the following, a classification, some examples, and a short description of the very different modes of action of drugs against diabetes is listed (for more details, e.g., see [26, 27, 29, 30]).

Insulin is always required for patients with T1DM (insulin dependent diabetes). Different types of insulin (rapid-, short-, regular-, intermediate- or long-acting) and various ways to ingest insulin (syringes, insulin pens, insulin pumps, and jet injectors) are available. In 2014 the FDA also approved a rapid-acting insulin (Afrezza) for inhalation.

Also injectable non-insulin medications exist, such as incretin mimetics (e.g., albiglutide, dulaglutide, exenatide, liraglutide) and amylin analogs (pramlintide). Incretin mimetics, which stimulate the pancreas to release insulin like the natural hormone glucagon-like petide-1 (GLP-1), prevent the pancreas to release too much glucagon and slow stomach emptying. Amylin analogs, which slow gastric emptying like the natural peptide hormone of pancreatic beta cells, inhibit the inappropriate postprandial secretion of glucagon and suppress appetite.

Oral medications mainly used for T2DM are briefly described in the following. Biguanides (e.g., metformin) decrease the glucose production in the liver by inhibition of glycogenolysis and gluconeogenesis, and enhance the utilization of glucose in peripheral tissues. Sulfonylureas (e.g., chlorpropamide, glimepiride, glipizide, glyburide, tolazamide, tolbutamide) stimulate pancreatic beta cells to release more insulin by blocking ATP-sensitive $\mathrm{K}^{+}$-channels in their cell membrane. Meglitinides (e.g., natelginide, repaglinide) stimulate beta cells to release more insulin in a way comparable to that of sulfonylureas. Thiazolidinediones (e.g., pioglitazone, rosiglitazone) stimulate the nuclear receptor peroxisome proliferator-activated receptor gamma (PPAR- $\gamma$ ) resulting in a reduction of insulin resistance in peripheral tissues and in the liver as well as in a decrease of gluconeogenesis in the liver. Dipeptidyl peptidase-4 (DPP-4) inhibitors (e.g., linagliptin, saxagliptin, sitagliptin, vildagliptin) increase the levels of glucagon-like peptide-1 (GLP-1) by inhibiting its fast degradation, thereby preventing increased glucagon release, stimulating an increase of insulin secretion and a decrease of gastric emptying. Alpha-glucosidase inhibitors (e.g., acarbose, miglitol) slow the breakdown of starch in the intestine resulting postprandial in lower amounts of absorbed glucose. And finally, sodium glucose cotransporter 2 (SGLT2) inhibitors or gliflozins (e.g., canagliflozin, dapagliflozin, empagliflozin) inhibit the reabsorption of glucose in the kidney, thereby causing excretion of glucose in the urine. This last group, the gliflozins which are the result of good knowledge about phlorizin and its SGLT-inhibitory activities, is of greatest interest in this review.

\section{Intestinal Glucose Absorption by SGLT1}

Dietary carbohydrates (e.g., starch, fructans, sucrose, lactose) are digested beginning in the mouth by salivary amylase, but mainly in the proximal small intestine by pancreatic enzymes ( $\alpha$-amylases) and brush border hydrolases (maltase, isomaltase, sucrase, and lactase) to yield monosaccharides (mainly glucose, galactose, fructose). Enterocytes in the duodenum and jejunum then absorb glucose and galactose with the help of SGLT1 located in their

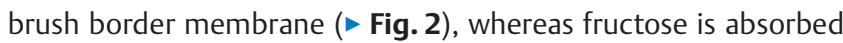
by the facilitative transporter GLUT5. SGLT1 is a cotransporter of glucose and sodium in a ratio of $1: 2$ [20,22-25]. The active transport by SGLT1 is enabled by a sodium electro-chemical potential gradient maintained by the activity of a $\mathrm{Na}^{+} / \mathrm{K}^{+}$-ATPase pump integrated into the basolateral membrane of the enterocytes ( $\vee$ Fig. 2). The basolateral membrane of enterocytes also contains GLUT2, which is responsible for the transport of glucose, galactose, and fructose into the blood ( $\bullet$ Fig. 2 ).

SGLT1 was originally discovered by expression cloning [31], cloned in 1989 [32], and structure models were first published in 1996 [33] and 1997 [34]. SGLT1 is a membrane protein consisting of 664 amino acids with 14 transmembrane $\alpha$-helices and an extracellular amino- and an intracellular carboxy-terminus [35, 36]. At a physiological membrane potential and at a physiological extracellular sodium concentration, the $K_{m}$ value for glucose is $0.5 \mathrm{mM}$ and for galactose $1 \mathrm{mM}$ [37]. A non-metabolized substrate for SGLT1 and SGLT2 often used experimentally is $\alpha$-methyl-D-glucopyranoside, which however is not transported by GLUTs. Phlorizin is a high-affinity, non-transported, competitive inhibitor of SGLT1 $(\mathrm{Ki} \sim 0.2 \mu \mathrm{M})$. In humans SGLT1 plays an important functional role in the small intestine and in the kidney. Partially low expression levels of SGLT1-mRNA have been detected 


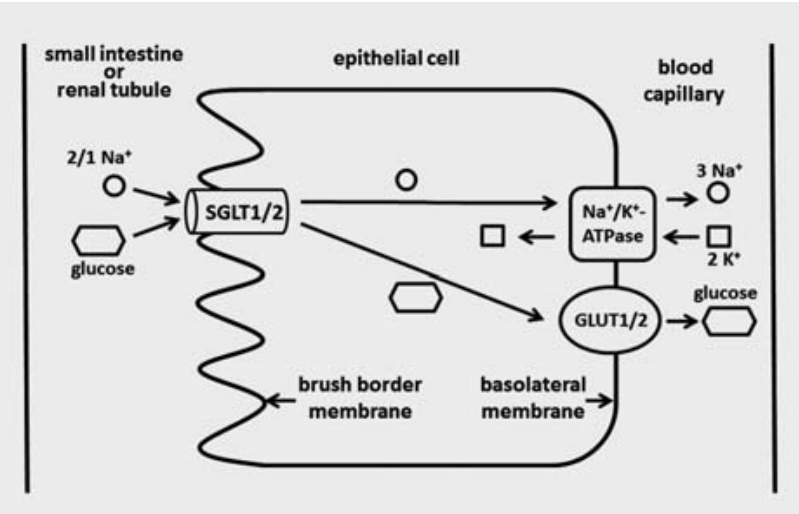

- Fig. 2 Glucose absorption: SGLTs which are responsible for glucose absorption are integrated into the brush border membranes of epithelial cells of the small intestine and of the proximal tubule of nephrons of the kidney. The basolateral membranes of epithelial cells contain GLUTs responsible for transfer of glucose into blood capillaries and $\mathrm{Na}^{+} / \mathrm{K}^{+}$-ATPase for maintenance of an electrochemical sodium gradient necessary for active transport of glucose by SGLTs against its concentration gradient. Small intestine: SGLT1 absorbs 1 glucose molecule together with 2 sodium ions and GLUT2 is integrated into the basolateral membrane. S1 and S2 segments of proximal tubules: SGLT2 reabsorbs 1 glucose molecule together with 1 sodium ion and GLUT2 transfers glucose back to the bloodstream. S3 segment of proximal tubules: SGLT1 reabsorbs 1 glucose molecule together with 2 sodium ions and GLUT1 is responsible for glucose transport into blood capillaries.

also in many other organs like heart, liver, lung, brain, and others. The real meaning and function in these organs is not always clear [25].

By the way, in the treatment of diarrhea an oral rehydration therapy (ORT) is often used to prevent dehydration. The formula for the WHO oral rehydration solution (ORS) is $2.6 \mathrm{~g} \mathrm{NaCl}, 2.9 \mathrm{~g}$ trisodium citrate dehydrate, $1.5 \mathrm{~g} \mathrm{KCl}$, and $13.5 \mathrm{~g}$ anhydrous glucose per liter of fluid [38]. Two sodium ions and one molecule of glucose are intestinal absorbed via SGLT1. For each cycle of transport also hundreds of molecules of water molecules enter the epithelial cell by cotransport to maintain the osmotic equilibrium [39-41]. A lot of water, in addition, is also absorbed by passive transport via SGLT1 [41]. The resultant absorption of sodium and water can achieve rehydration even while diarrhea continues.

\section{The Kidney: Filtration and Reabsorption of Glucose by SGLT2 and SGLT1}

In the nephrons of the kidney (about 1 million per kidney) blood plasma is filtered (ultrafiltration) through the capillaries of the glomerulus into the surrounding Bowman's capsule. The glomerular filtrate (about $170 \mathrm{~L}$ of primary urine/day) is then passed into the renal tubule where it is further processed by reabsorption of water, ions, lactate, urea, amino acids, and glucose to form the final urine (about 1.5-2 L/day). Reabsorption is an energy (ATP) consuming process [42].
In healthy adults, the kidneys are filtering $160-180 \mathrm{~g}$ of glucose per day. Nearly all of it is reabsorbed within the proximal tubules and less than $1 \%$ is excreted in the urine. Reabsorption of glucose has a maximum value, the renal threshold of glucose $\left(R T_{G}\right)$. When the blood concentration for glucose is higher than about $200 \mathrm{mg} / \mathrm{dL}(10-11 \mathrm{mmol} / \mathrm{L})$ or the glucose load exceeds about $220 \mathrm{mg} / \mathrm{min}$ (hyperglycemia), this threshold is exceeded and glucose is excreted in the final urine (glycosuria). This is an indicator of diabetes [26, 27, 41, 42].

Reabsorption of glucose is done in the proximal tubules of the nephrons, where various (sub)-types of glucose transporters are involved. The proximal tubule can be divided into two sections (pars convoluta and pars recta) and, regarding ultrastructure, into three segments (S1, S2, S3). The pars convoluta, where the epithelial cells have a very well developed luminal brush border, would correspond to S1 and the first part of S2. In S3 the epithelium is cubical simple. Transition of S1 via S2 to S3 is gradual $[42,43]$.

In segment S1 and S2, the brush border of epithelial cells contains SGLT2 which is a high-capacity, low-affinity cotransporter of glucose and sodium ( $\triangleright$ Fig. 2 ). The coupling ratio for SGLT2 is $1 \mathrm{Na}^{+}$-ion/ 1 glucose molecule [22,43]. SGLT2 consists of 672 amino acids and has 14 transmembrane $\alpha$-helices in topology. The energy for the active transport of glucose against its concentration gradient is derived from a sodium electrochemical potential gradient. This gradient is maintained by the activity of sodium-potassium adenosine triphosphatase $\left(\mathrm{Na}^{+} / \mathrm{K}^{+}\right.$-ATPase) pumps integrated into the basolateral membrane of the epithelial cells moving 3 sodium ions out of the cell into the blood and 2 potassium ions from the blood into the epithelial cell ( $\bullet$ Fig. 2 ). Its basolateral membrane also contains GLUT2 performing the passive transport of glucose from the plasma of the epithelial cell into the blood plasma ( $\triangleright$ Fig. 2). SGLT2 under normal conditions is responsible for about $90 \%$ of glucose reabsorption from the primary urine (corresponding to $140-160 \mathrm{~g}$ per day) [22-24, 43].

Remaining glucose is reabsorbed at the luminal membrane of segment S3, where SGLT1 is integrated into the brush border of epithelial cells ( $\bullet$ Fig. 2 ). As in the small intestine, SGLT1 is a lowcapacity, high-affinity cotransporter of glucose and sodium in a $1: 2$ ratio $[22-24,43]$. Again, this active transport is enabled by a sodium electrochemical potential gradient maintained by the activity of a $\mathrm{Na}^{+} / \mathrm{K}^{+}$-ATPase pump integrated into the basolateral membrane of the epithelial cell ( $\bullet$ Fig. 2). Its basolateral membrane in addition contains GLUT1 responsible for the transport of glucose from the epithelial cell into the blood ( $\triangleright$ Fig. 2) [22-24, 43].

\section{Gliflozins as SGLT Inhibitors for Treatment of Diabetes}

The above mentioned synthetic C-glycoside analogs of phlorizin, the gliflozins (dapagliflozin, canagliflozin, empagliflozin), have been developed for treatment of T2DM with the goals of good bioavailability, high stability, and high selectivity for inhibition of SGLT2 in the kidneys in order to reduce blood glucose levels by excretion of excess glucose via the urine [22-25]. Gliflozins are applied orally and are well absorbed in the small intestine. Inhibition 
of SGLT1 in the small intestine is avoided by fast absorption and high selectivity for SGLT2. For dapagliflozin the inhibition of SGLT2 versus SGLT1 is 1200-fold higher (SGLT2: IC $50=1.2 \mathrm{nM}$; SGLT1: $I_{50}=1400 \mathrm{nM}$ ), and for canagliflozin (SGLT2: IC $50=4.2 \mathrm{nM}$; SGLT1: $\quad \mathrm{CC}_{50}=660 \mathrm{nM}$ ) a 160 -fold. For empagliflozin (SGLT2: $I_{50}=3.1 \mathrm{nM}$; SGLT1: IC $50=8300 \mathrm{nM}$ ) a 2700-fold higher inhibitory activity against SGLT2 compared to SGLT1 has been described [18-20]. Gliflozins are filtrated in the glomeruli of the nephrons of the kidney and inhibit SGLT2 in the S1 and S2 segment of the proximal tubule. A decrease of tubular glucose reabsorption of only $30-50 \%$ can be achieved by gliflozins [44-46] because, although more glucose is reaching segment S3 due to inhibition of SGLT2, an increased proportion of it can be reabsorbed by SGLT1. In various clinical studies with gliflozins it could be shown that a prolonged application decreases fasting and nonfasting plasma glucose levels by $20-50 \mathrm{mg} / \mathrm{dL}$ [20] resulting in a reduction of $\mathrm{HbA} 1 \mathrm{c}$ by $0.5-1.5 \%$ in patients with $\mathrm{HBA} 1 \mathrm{c}$ of up to $9 \%$ [20] and can cause some loss in body weight $(1-3 \mathrm{~kg})$ combined with decreased visceral adiposity $[47,48]$. In addition, general recommendations for T2DM are weight reduction programs with healthy diet and physical activity. Gliflozins can be used as monotherapy but also in combination with other antidiabetics such as metformin or thiazolidinediones [49], dipeptidyl peptidase-4 (DPP-4) inhibitors [50], or insulin [47]. The incidence of hypoglycemia during SGLT2 inhibitor treatment is generally low, but also depends on the use of other antidiabetic drugs in combination therapy [48]. The risks for bacterial urinary tract infections as well as for genital mycotic infections are increased by treatment with gliflozins (up to $9 \%$ ) due to a higher glucose level in urine. Infections normally are mild and can successfully be treated with standard antibiotics or antifungals [51,52]. Compared to men these side effects are more often observed in women.

For a long time, there were concerns that intestinal inhibition of SGLT1 could result in gastrointestinal discomfort such as flatulence, diarrhea, and general glucose and galactose malabsorption. In reality, these possible side-effects seem to be rare especially because normally only a delay of intestinal glucose absorption can be achieved which, however, can be quite useful. Postprandial plasma glucose levels decrease and more glucose in the small intestine has contact with $\mathrm{K}$ - and L-cells. Both express SGLT1 and react to increased glucose levels and both secrete incretins. K-cells secret the gastric inhibitory polypeptide (GIP; also known as glucose-dependent insulinotropic peptide) stimulating insulin secretion and L-cells, among others, secrete glucagon-like peptide-1 (GLP-1) [53, 54]. L-cells are spread as single cells throughout the intestinal tract and found in the duodenum and jejunum, but most of them in the ileum and colon. If due to SGLT1 inhibition the glucose level in the small intestine is high over a longer period of time and more glucose reaches the ileum, its L-cells release more GLP-1. GLP-1 stimulates the secretion of insulin from pancreatic beta cells, prevents the pancreas to release too much glucagon which would cause glycogenolysis in the liver, slows gastric emptying, and decreases appetite $[53,54]$. Therefore, a delay in glucose absorption by moderate inhibition of intestinal SGLT1 can be helpful in diabetes treatment.

These facts, together with the already above mentioned findings that highly selective SGLT2 inhibitors can decrease tubular glucose reabsorption only up to $50 \%$ due to increased reabsorption of glucose by SGLT1 in segment S3, nowadays intensify the search for dual SGLT1/SGLT2 inhibitors. Sotagliflozin (formerly LX-4211) is a dual SGLT1/SGLT2 inhibitor under development with an IC 50 of $1.8 \mathrm{nM}$ against SGLT2 and of $36 \mathrm{nM}$ against SGLT1, and thus a SGLT2/SGLT1 selectivity of 20 [20,21]. In a clinical study, sotagliflozin ( 150 or $300 \mathrm{mg}$ daily) in monotherapy of T2DM could reduce a baseline $\mathrm{HbA} 1 \mathrm{c}$ of $8.1 \%$ by $0.66 \%$ or $0.76 \%$, respectively [55]. An increased secretion of GLP-1 after uptake of glucose-rich food and treatment with sotagliflozin could be observed [57]. In another clinical study sotagliflozin was given in combination with metformin and the results suggested that lowered fasting plasma glucose concentrations and reduced $\mathrm{HbA} 1 \mathrm{c}$ values at least partly were caused by intestinal SGLT1 inhibition [56].

\section{Natural Products as SGLT Inhibitors}

The important role of the natural compound phlorizin isolated from the bark of apple trees (Malus sp.) in the development of SGLT2-inhibitors has already been mentioned in detail. In addition to apple tree bark, Phlorizin also is found in apple tree leaves and fruits [58], and in some other members of the family Rosaceae, such as in strawberry fruits (Fragaria x ananassa Duch.) [59], in rose hips (Rosa canina L.) [60], or in the bark of pear (Pyrus communis L.) [58] but not in their fruits [61]. Phlorizin also could be detected in a few other plant species belonging to different families, but in total only low amounts can be found in plants other than apple trees [58]. The biosynthesis of phlorizin could be described in detail also with the help of recombinant enzymes; mainly involved are a NADPH-dependent dehydrogenase, a chalcone synthase, and an UDP-glucose:phloretin 2'-O-glycosyltransferase [58].

Controlling of postprandial hyperglycemia is thought to be important for the prevention and treatment of T2DM. The interest in food constituents which can be used for this purpose is growing. Therefore, polyphenols and thus also phlorizin containing apple extracts have been investigated with this objective.

A specific apple fruit extract, containing $16 \mathrm{mg}$ phlorizin, $12 \mathrm{mg}$ quercetin, and $6 \mathrm{mg}$ chlorogenic acid as main polyphenols per $100 \mathrm{mg}$ dry mass, was used in investigations with ten healthy lean men [62]. After a 1-day period without consumption of flavonoid-rich food and a 12-h fast they had to ingest $2.8 \mathrm{~g}$ of the capsuled apple extract 30 min before an oral glucose tolerance test (OGTT) with $75 \mathrm{~g}$ glucose. Blood glucose and insulin levels were determined up to 180 min after OGTT, as well as urine glucose levels up to $24 \mathrm{~h}$ after OGTT. Postprandial venous blood glucose levels were not significantly different compared to controls (OGGT performed with the same men without prior to donation of apple extract), but incremental areas under the curve (iAUC) for blood glucose 15, 30, and 45 min after OGGT were significantly lower. Also, significantly lower plasma insulin levels (iAUC up to $90 \mathrm{~min}$ after OGTT) compared to controls could be detected. A 4.9-fold higher glucose output in urine was observed in the first $3 \mathrm{~h}$ after ingestion of apple extract, whereas in controls no changes in urinary glucose levels could be seen [62]. 
The above described extract also inhibited effectively human SGLT1 expressed in Xenopus laevis oocytes and in mouse intestinal segments [62]. For chlorogenic acid in the Xenopus oocyte SGLT1 test system, no significant inhibition of SGLT1 could be proven, whereas for quercetin and phloretin a moderate inhibition $\left(\mathrm{IC}_{50}=0.6 \mathrm{mM}\right.$ and $0.3 \mathrm{mM}$, respectively) and for phlorizin a strong inhibition $\left(\mathrm{IC}_{50}=0.5 \mu \mathrm{M}\right)$ were shown. For phlorizin and the apple extract, Ki values of $1.1 \mu \mathrm{g} / \mathrm{mL}$ and $0.14 \mu \mathrm{g} / \mathrm{ml}$, respectively, have been determined. When tested in everted jejunal rings of mice, the apple extract and phlorizin inhibited the uptake of methyl- $\alpha$-D-glucopyranoside ( $1 \mathrm{mM}$ ) with calculated $\mathrm{EC}_{50}$ values of $9 \mu \mathrm{g} / \mathrm{mL}$ and $4 \mu \mathrm{g} / \mathrm{mL}$, respectively [62]. The inhibition of SGLT1 by apple extract and phlorizin was competitive and reversible in all test systems.

Also, C57BL/6 N mice after a high-fat diet with resulting obesity and hyperglycemia were subjected to an OGGT [62]. In obese mice, in contrast to control mice, the apple extract and phlorizin significantly reduced the increase of blood glucose concentration over a time period of up to 60 min by $40-70 \%$.

Phlorizin can be effectively hydrolyzed by lactase phlorizin hydrolase (LPH), an enzyme that is expressed in the brush border membrane of the small intestine. It is a glycoprotein with two catalytic sites: one is responsible for hydrolyzing lactose, the main carbohydrate in milk (important for infants and young children), and the other exhibits a broad activity against various flavonoids and glycosyl-N-acylsphingosines [63-65]. LPH is, for example, responsible for the hydrolysis of phlorizin, quercetin-4'-O-glucoside, kaempferol-3-O-glucoside, apigenin-7-O-glucoside, luteolin-3'-7-O-diglucoside, genistein-7-O-glucoside, and daidzein-7O-glucoside $[61,62,64,65]$. Phloretin, the resultant aglycon of hydrolysis of phlorizin by LPH, is thought to be taken up by enterocytes in the small intestine, to inhibit GLUT2 expressed in their basolateral membrane, and, thus, to cause a delay in glucose absorption and to lower blood glucose levels $[63,66]$. Comparable effects are also discussed for quercetin as LPH-hydrolysis product of quercetin glycoside rich foods $[63,66]$.

In investigations of the influence of several types of apple juices (clear and cloudy with twice as high phlorizin content) on glucose absorption ( $25 \mathrm{~g}$ glucose load) in healthy volunteers, a delay of glucose absorption for the first 30 min could be demonstrated accompanied by a reduced plasma insulin level [67], and phlorizin and other polyphenols were thought to be responsible for this effect. It was shown that the release of intestinal hormones was also influenced, especially by the phlorizin rich cloudy apple juice. The production of glucose-dependent insulinotropic polypeptide produced by K-cells in the proximal region of the gut was suppressed, whereas the concentrations of glucagon like peptide 1 (GLP-1) produced by L-cells in the more distal regions of the gut increased [67]. Comparable results have been observed in studies with mice treated with phlorizin containing extracts from apple leaves [68] and also after administration of the synthetic dual SGLT1/SGLT2 inhibitor LX4211 (= sotagliflozin) [69].

An apple powder prepared from unripe apple fruits (Malus domestica Borkh., cultivar Auksis) contained $12.6 \mathrm{~g} / \mathrm{kg}$ of phlorizin. Acute ingestion of the apple powder $(25 \mathrm{~g})$ by six healthy female volunteers with a body mass index (BMI) of $>25 \mathrm{~kg} / \mathrm{m}^{2}$ reduced the postprandial glucose response in an oral glucose tolerance test ( $50 \mathrm{~g}$ glucose) after 15 to $30 \mathrm{~min}$ about two-fold and increased the urinary glucose excretion after 2 to 4 hours about five-fold [70]. In the plasma, only very low concentrations of phloretin-2'-O-glucuronide were found, whereas in the urine the three metabolites phloretin-2'-O-glucuronide (ranging from 20 $250 \mathrm{mg} / \mathrm{L})$, phloretin-O-glucuronide $(0.2-16 \mathrm{mg} / \mathrm{L})$ and phloretin $(0.4-8 \mathrm{mg} / \mathrm{L})$ could be detected [70].

For some other flavonoids, also an inhibitory activity against SGLTs has been described.

Two flavanone derivatives which are isolated from the roots of Sophora flavescens Ait. (Fabaceae) and used in TCM, kurarinone and sophoraflavanone, showed good SGLT-inhibitory activities (SGLT1: IC $50=10.4$ and $18.7 \mu \mathrm{M}$, respectively; SGLT2: IC $_{50}=1.7$ and $4.1 \mu \mathrm{M}$, respectively) [71]. Also, two isoflavone glycosides from the same source showed a comparable SGLT2-inhibitory activity, but their activity against SGLT1 has not been determined [72].

The glycosidic flavonoid tiliroside was shown to be a noncompetitive inhibitor of pancreatic $\alpha$-amylase $\left(\mathrm{IC}_{50}=0.28 \mathrm{mM}\right)$ and could suppress the increase in postpandial plasma glucose levels in male ICR mice. In addition, tiliroside in vitro in human intestinal Caco- 2 cells transfected with SGLT1 showed an inhibitory activity against SGLT1 and GLUT2 indicating an additional role in reduced intestinal glucose absorption [73].

Normally, flavonoids in foods are present as intact glycosides and their bioavailability has been investigated by various groups [74]. Various mechanisms and sites of absorption are described. Most glucosides (and their aglycons) seem to be absorbed in the small intestine, and often quercetin glucosides have been used for the characterization of transport. In the past, also SGLT1 has been proposed to be responsible for the absorption of quercetin glycosides, as for example the uptake of quercetin-4'-O-glucoside into SGLT1-trasfected Caco-2 cells was inhibited by glucose or phlorizin [75]. Also for quercetin-3-O-glucoside a cellular uptake via SGLT1 has been proposed [76]. Then, a possible role of lactase phlorizin hydrolase (LPH) for the hydrolysis of flavonoid glycosides at the brush border of the small intestine and a following absorption of the aglycons via passive processes has been discussed and investigated in a rat everted-jejunal sac model [63]. The results suggested a transport of the aglycon quercetin by a mechanism independent of SGLT1, but a transport of quercetin-4'-O-glucoside also via SGLT1. Then, however, with the help of directly measuring transport currents in Xenopus oocytes expressing human SGLT1 it clearly could be demonstrated that some flavonoids can inhibit SGLT1, but none is a substrate for transport by SGLT1 [77]. Neither aglycons nor any glycosides of quercetin, luteolin, apigenin, naringenin, pelarginidin, daidzein, genistein, or okanin were transported by SGLT1. Best SGLT1 inhibitors were O-glycosides with glucose attached at position 4' like luteolin-4'-O-glucoside and quercetin- $4^{\prime}$-O-glucoside $\left(\mathrm{IC}_{50}=0.10\right.$ and $0.17 \mathrm{mM}$, respectively), but surprisingly also the $\mathrm{C}$-glycoside apigenine-6-C-glucoside $\left(\mathrm{IC}_{50}=0.55 \mathrm{mM}\right)$ and the aglycons luteolin, naringenin and quercetin $\left(\mathrm{IC}_{50}=0.22\right.$ and 0.53 , respectively, and $\left.0.62 \mathrm{mM}\right)$ showed appreciable SGLT1 inhibitory activity [77].

Inhibition of SGLT1 by quercetin-3-O-glucoside and quercetin4'O-glucoside had been described already earlier by an in vitro jejunal mucosal uptake method using $\alpha$-methyl-D-glucopyranoside 
as substrate, and a competitive type of inhibition was proposed [78]. SGLT1-containing brush-border membrane vesicles from pig jejunum were also used to demonstrate the inhibition of SGLT1 by quercetin-3-O-glucoside and quercetin-4'-O-glucoside [79].

With the growing interest in dietary compounds that may help to prevent the development of diabetes (T2DM) also onions (Allium cepa L.) became a subject of interest. An onion extract containing quercetin-4'-O-glucoside, quercetin 3,4'-O-diglucoside, and quercetin $(9.5 \mathrm{mg}, 5.4 \mathrm{mg}$ and $5.4 \mathrm{mg}$, respectively, per $100 \mathrm{mg}$ dry mass) as main flavonoids was used to investigate the inhibition of SGLT1 and GLUT2 as well as antihyperglycemic effects in mice and human volunteers [80]. Human SGLT1 expressed in Xenopus laevis oocytes was reversibly inhibited by the onion extract $\left(\mathrm{IC}_{50}=325 \mu \mathrm{g} / \mathrm{mL}\right)$. Quercetin-4' O-glucoside was the main inhibitory ingredient (IC50 $=0.17 \mathrm{mM})$, whereas quercetin showed only a moderate inhibitory activity $\left(\mathrm{IC}_{50}=0.62 \mathrm{mM}\right)$, and quercetin-3,4' -glucoside had no inhibitory activity at all [80]. Inhibition of human GLUT2 expressed in CRNA injected Xenopus laevis oocytes could be shown for the onion extract and mainly for quercetin (65\% inhibition of uptake of radiolabeled 2-deoxy-D-glucose at a concentration of $100 \mu \mathrm{M}$ ) [80]. The onion extract also inhibited the absorption of $\alpha$-methyl-glucose in murine jejunal tissues. When obese hyperglycemic $\mathrm{C} 57 \mathrm{BL} / 6$ mice were subjected to an OGTT, the onion extract reduced the increase in blood glucose concentration with a significant decrease in the iAUC over a time period of up to $120 \mathrm{~min}$ [80]. These effects are thought to be based mainly on inhibition or at least on a delay of intestinal glucose absorption. In healthy young men, however, the administration of the onion extract $(3.1 \mathrm{~g}) 30$ min before an OGTT (75 g glucose) did cause no changes in postprandial glucose and insulin levels or in urinary glucose excretion, which is discussed to be predominantly due to an insufficient dosing of the onion extract [80].

Investigations on the influence of natural compounds on glucose transporters have also been performed with green tea polyphenols. In a rat model, green tea decoctions, containing the typical polyphenols as well as a 2:1-mixture of synthetic epigallocatechin gallate and epigallocatechin, inhibited SGLT1 activity, increased GLUT2-activity, and improved glucose tolerance [81]. If the rats were treated for 6 weeks with green tea decoctions, significantly reduced SGLT1- and increased GLUT2-mRNA levels were detected.

SGLT inhibitory activity is also known for some alkaloids. From Alstonia macrophylla Wall. (Apocynaceae) especially the two picraline-type alkaloids, namely 10-methoxy-N(1)-methylburnamine17-O-veratrate and allstiphyllanine D, inhibited SGLTs at low concentrations (SGLT1: IC $50=4.0$ and $5.0 \mu \mathrm{M}$, respectively; SGLT2: $\mathrm{IC}_{50}=0.5$ and $2.0 \mu \mathrm{M}$, respectively) [82].

\section{Conclusions}

In the prevention of the development of type 2 diabetes and in its treatment, the control of postprandial hyperglycemia is very important. The interest especially in appropriate flavonoid rich food constituents and preparations with SGLT1 inhibitory activity is growing and the search for useful preparations is going on. It re- mains exciting which new natural compounds with SGLT inhibiting activity and mixtures thereof will still be discovered, tested and used directly or as model for synthetic SGLT inhibitors in the treatment of diabetes.

Phlorizin was and still is an important lead compound for the development of SGLT2- and, meanwhile, also for SGLT1- or dual SGLT2/SGLT1-inhibitors. Combined intestinal SGLT1 inhibition and renal SGLT2 plus SGLT1 inhibition have the potential for a delay of intestinal glucose absorption combined with a stimulation of pancreatic insulin release induced by GLP-1 from intestinal Lcells as well as for a more effective inhibition of renal glucose reabsorption. Thus, with a smile we can state: Back to the roots (of apple trees whose bark contains phlorizin as valuable example for SGLT inhibition).

\section{Conflict of Interest}

The author declares no conflict of interest.

\section{References}

[1] Petersen C. Analyse des Phloridzins. Ann Acad Sci Fr 1835; 15: 178

[2] Zemplen G, Bognar R. Synthese des natürlichen Phlorrhizins. Chem Ber 1942; 75: 1040

[3] De Koninck L. Observations sur les proprieties febrifuges de las phloridzine. Bull Soc Med Gand 1836; 1: 75-110

[4] Von Mering J. Über künstlichen Diabetes. Centralbl Med Wiss 1886; 22 531

[5] Stiles PG, Lusk G. On the action of phlorizin. Am J Physiol 1903; 10: 6179

[6] Chassis $\mathrm{H}$, Jolliffe $\mathrm{N}$, Smith $\mathrm{H}$. The action of phlorizin on the excretion of glucose, xylose, sucrose, creatinine, and urea by man. J Clin Invest 1933; 12: 1083-1089

[7] Crane RK, Miller D, Bihler I. The Restrictions on possible Mechanisms of intestinal active Transport of Sugars. In: Kleinzeller A, Kotyk A, eds. Intestinal Absorption. London: Academic Press; 1961: 439-449

[8] Alvarado FC, Crane RK. Phlorizine as a competitive inhibitor of the active transport of sugars by hamster small intestine in vitro. Biochim Biophys Acta 1962; 56: 170-172

[9] Vick HD, Deidrich DF. Reevaluation of renal tubular glucose transport inhibition by phlorizin analogs. Am J Physiol 1973; 224: 552-557

[10] Amsler K, Cook JS. Development of a $\mathrm{Na}^{+}$-dependent hexose transport in a cultured line of porcine kidney cells. Am J Physiol 1982; 242: C94-C101

[11] Lee WS, Wells RG, Hediger MA. The high affinity Na/glucose cotransporter: reevaluation and distribution of expression. J Biol Chem 1994; 268: $12032-12039$

[12] Ehrenkranz JRL, Lewis NG, Kahn CR, Roth J. Phlorizin: a review. Diabetes Metab Res Rev 2005; 21: 31-38

[13] Oku A, Ueta K, Arakawa K, Ishihara T, Nawano M, Kuronuma Y, Matsumoto M, Saito A, Tsujihara K, Anai M, Asano T, Kanai Y, Endou H. $\mathrm{T}-1095$, an inhibitor of renal $\mathrm{Na}^{+}$-glucose cotransporters, may provide a novel approach to treating diabetes. Diabetes 1999; 48: 1794-1800

[14] Katsuno K, Fujimori Y, Takemura Y, Hiratochi M, Itoh F, Komatsu Y, Fujikura $\mathrm{H}$, Isaji M. Sergliflozin, a novel selective inhibitor of low-affinity sodium glucose cotransporter (SGLT2), validates the critical role of SGLT2 in renal glucose reabsorption and modulates plasma glucose level. J Pharmacol Exp Ther 2007; 320: 323-330

[15] Fujimori Y, Katsuno K, Nakashima I, Ishikawa-Takemura Y, Fujikura H, Isaji M. Remogliflozin etabonate, in a novel category of selective low-affinity sodium glucose cotransporter (SGLT2) inhibitors, exhibits antidia- 
betic efficacy in rodent models. J Pharmacol Exp Ther 2008; 327: 268276

[16] Link JT, Sorensen BK. A method for preparing C-glycosides related to phlorizin. Tetrahedron Lett 2000; 41: 9213-9217

[17] Meng W, Ellsworth BA, Nirschl AA, McCann PJ, Patel M, Girotra RN, Wu G, Sher PM, Morrison EP, Biller SA, Zahler R, Deshpande PP, Pullockaran A, Hagan DL, Morgan N, Taylor JR, Obermeier MT, Humphreys WG, Khanna A, Discenza L, Robertson JG, Wang A, Han S, Wetterau JR, Janovitz EB, Flint OP, Whaley JM, Washburn WN. Discovery of dapagliflozin: A potent, selective renal sodium-dependent glucose cotransporter 2 (SGLT2) inhibitor for the treatment of type 2 diabetes. J Med Chem 2008; 51: 1145-1149

[18] Nomura S, Sasamaki S, Hongu M, Kawanishi E, Koga Y, Sakamoto T, Yamamoto Y, Ueta K, Kimata H, Nakayama K, Tsuda-Tsukimoto M. Discovery of canagliflozin, a novel $\mathrm{C}$-glucoside with thiophene ring, as sodium-dependent glucose cotransporter 2 inhibitor for the treatment of type 2 diabetes mellitus. J Med Chem 2010; 53: 6355-6360

[19] Grampler R, Thomas L, Eckhardt M, Himmelsbach F, Sauer A, Sharp DE, Bakker RA, Mark M, Klein T, Eickelmann P. Empagliflozin, a novel selective sodium glucose cotransporter-2 (SGLT-2) inhibitor: Characterisation and comparison with other SGLT-2 inhibitors. Diabetes Obes Metab 2012; 14: 83-90

[20] Mudaliar S, Polidori D, Zambrowicz B, Henry RR. Sodium-glucose cotransporter inhibitors: effects on renal and intestinal glucose transport. Diabetes Care 2015; 38: 2344-2353

[21] Lapuerta P, Zambrowicz B, Strumph P, Sands A. Development of sotagliflozin, a dual sodium-dependent glucose transporter 1/2 inhibitor. Diab Vasc Dis Res 2015; 12: 101-110

[22] Vallon V. The mechanisms and therapeutic potential of SGLT2 inhibitors in diabetes mellitus. Annu Rev Med 2015; 66: 255-270

[23] Song P, Onishi A, Koepsell H, Vallon V. Sodium glucose cotransporter SGLT1 as a therapeutic target in diabetes mellitus. Expert Opin Ther Targets 2016; 20: 1109-1125

[24] Madaan T, Akhtar M, Abul Najmi SK. Sodium glucose cotransporter 2 (SGLT2) inhibitors: Current status and future perspective. Eur J Pharm Sci 2016; 93: 244-252

[25] Koepsell H. The Na+-D-Glucose cotransporters SGLT1 and SGLT2 are targets for the treatment of diabetes and cancer. Pharmacol Ther 2017; 170: $148-165$

[26] Cefalu WT, ed. Standards of Medical Care in Diabetes - 2016. Diabetes Care 2016; 39: S1-S112

[27] Marín-Peñalver J], Martín-Timón I, Sevillano-Collantes C, del CañizoGómez FJ. Update on the treatment of type 2 diabetes mellitus. World J Diabetes 2016; 7: 354-395

[28] World Health Organization. Global Report on Diabetes 2016. Geneva: World Health Organization; 2016

[29] Gururaj Setty S, Crasto W, Jarvis J, Khunti K, Davies MJ. New insulins and newer insulin regimens: a review of their role in improving glycaemic control in patients with diabetes. Postgrad Med J 2016; 92: 152-164

[30] Bennett WL, Maruthur NM, Singh S, Segal JB, Wilson LM, Chatterjee R, Marinpopoulos SS, Puhan MA, Ranasinghe P, Block L, Nocholson WK, Hutfless S, Bass EB, Bolen S. Comparative effectiveness and safety of medications for type 2 diabetes: an update including new drugs and 2drug combinations. Ann Intern Med 2011; 154: 602-613

[31] Hediger MA, Coady MJ, Ikeda TS, Wright EM. Expression cloning and cDNA sequencing of the $\mathrm{Na}^{+} /$glucose co-transporter. Nature 1987; 330 : 379-381

[32] Hediger MA, Turk E, Wright EM. Homology of the human intestinal $\mathrm{Na}^{+}$/glucose and Escherichia coli $\mathrm{Na}^{+}$/proline cotransporters. Proc Natl Acad Sci 1989; 86: 5748-5752

[33] Turk E, Kerner C], Lostao MP, Wright EM. Membrane topology of the human $\mathrm{Na}^{+}$/glucose cotransporter SGLT1. J Biol Chem 1996; 271: 19251934
[34] Turk, Wright EM. Membrane topology motifs in the SGLT (1996) cotransporter family. J Membr Biol 1997; 159: 1-20

[35] Chen XZ, Coady MJ, Jackson F, Berteloot A, Lapointe JY. Thermodynamic determination of the $\mathrm{Na}^{+}$: glucose coupling ratio for the human SGLT1 cotransporter. Biophys J 1995; 69: 2405-2414

[36] Mackenzie B, Loo DD, Wright EM. Relationships between $\mathrm{Na}^{+} /$glucose cotransporter (SGLT1) currents and fluxes. J Membr Biol 1998; 162: 101-106

[37] Wright EM, Loo DDF, Hirayama BA. Biology of human sodium glucose transporters. Physiol Rev 2011; 91: 733-794

[38] World Health Organization. The treatment of diarrhea, a manual for physicians and other senior health workers. Geneva: World Health Organization; 2005

[39] Loo DD, Wright EM, Zeuthen T. Water pumps. J Physiol 2002; 542: 53-60

[40] Gagnon MP, Bissonnette P, Deslandes LM, Wallendorff B, Lapointe JY. Glucose accumulation can account for the initial water flux triggered by $\mathrm{Na}^{+}$/glucose cotransport. Biophys J 2004; 86: 125-133

[41] Erokhova L, Horner A, Ollinger N, Siligan C, Pohl P. The sodium glucose cotransporter SGLT1 is an extremely efficient facilitator of passive water transport. J Biol Chem 2016; 291: 9712-9720

[42] Preuss HG. Basics of renal anatomy and physiology. Clin Lab Med 1993; 13: $1-11$

[43] Vallon V. The proximal tubule in the pathophysiology of the diabetic kidney. Am J Physiol Regul Integr Comp Physiol 2011; 300: R1009-R1022

[44] DeFronzo RA, Hompesch M, Kasichayanula S, Liu X, Hong Y, Pfister M, Morrow LA, Leslie BR, Boulton DW, Ching A, LaCreta FP, Griffen SC. Characterization of renal glucose reabsorption in response to dapagliflozin in healthy subjects and subjects with type 2 diabetes. Diabetes Care 2013; 36: 3169-3176

[45] Gallo LA, Wright EM, Vallon V. Probing SGLT2 as a therapeutic target for diabetes: Basic physiology and consequences. Diab Vasc Dis Res 2015; 12: $78-89$

[46] Liu ], Lee TW, DeFronzo RA. Why do SGLT2 inhibitors inhibit only 30-50\% of renal glucose reabsorption in humans? Diabetes 2012; 61: 21992204

[47] Rosenstock J, Jelaska A, Frappin G, Salsali A, Kim G, Woerle HJ, Broedl UC. Improved glucose control with weight loss, lower insulin doses, and no increased hypoglycemia with empagliflozin added to titrated multiple daily injections of insulin in obese inadequately controlled type 2 diabetes. Diabetes Care 2014; 37: 1815-1823

[48] Nauck MA. Update on developments with SGLT2 inhibitors in the management of type 2 diabetes. Drug Des Devel Ther 2014; 8: 1335-1380

[49] Blevins T. Combination therapy for patients with uncontrolled type 2 diabetes mellitus: Adding empagliflozin to pioglitazone or pioglitazone plus metformin. Expert Opin Drug Saf 2015; 14: 789-793

[50] DeFronzo RA, Lewin A, Patel S, Liu D, Kaste R, Woerle H], Broedl UC. Combination of empagliflozin and linagliptin as second-line therapy in subjects with type 2 diabetes inadequately controlled on metformin. Diabetes Care 2015; 38: 384-393

[51] Kushner P. Benefits/risks of sodium-glucose co-transporter 2 inhibitor canagliflozin in women for the treatment of type 2 diabetes. Women's Health (Lond) 2016; 12: 379-388

[52] Nyirjesy P, Sobel JD, Fung A, Mayer C, Capuano G, Way K, Usiskin K. Genital mycotic infections with canagliflozin, a sodium glucose co-transporter 2 inhibitor, in patients with type 2 diabetes mellitus: a pooled analysis of clinical studies. Curr Med Res Opin 2014; 30: 1109-1119

[53] Campbell JE, Drucker DJ. Pharmacology, physiology, and mechanisms of incretin hormone action. Cell Metab 2013; 17: 819-837

[54] Spreckley E, Murphy KG. The L-cell in nutritional sensing and the regulation of appetite. Front Nutr 2015; 2: 23

[55] Zambrowicz B, Freiman J, Brown PM, Frazier KS, Turnage A, Bronner ], Ruff D, Shadoan M, Banks P, Mseeh F, Rawlins DB, Goodwin NC, Mabon 
R, Harrison BA, Wilson A, Sands A, Powell DR. LX4211, a dual SGLT1/ SGLT2 inhibitor, improved glycemic control in patients with type 2 diabetes in a randomized, placebo-controlled trial. Clin Pharmacol Ther 2012; 92: 158-169

[56] Rosenstock J, Cefalu WT, Lapuerta P, Zambrowicz B, Ogbaa I, Banks P, Sands A. Greater dose-ranging effects on A1C levels than on glucosuria with LX4211, a dual inhibitor of SGLT1 and SGLT2, in patients with type 2 diabetes on metformin monotherapy. Diabetes Care 2015; 38: 431-438

[57] Sands AT, Zambrowicz BP, Rosenstock ], Lapuerta P, Bode BW, Garg SK, Buse JB, Banks P, Heptulla R, Rendell M, Cefalu WT, Strumph P. Sotagliflozin, a dual SGLT1 and SGLT2 inhibitor, as adjunct therapy to insulin in type 1 diabetes. Diabetes Care 2015; 38: 1181-1188

[58] Gosch C, Halbwirth H, Stich K. Phloridzin: biosynthesis, distribution and physiological relevance in plants. Phytochem 2010; 71: 838-843

[59] Hilt P, Schieber A, Yildirim C, Arnold G, Klaiber I, Conrad J, Carle R. Detection of phloridzin in strawberries (Fragaria $\mathrm{x}$ ananassa Duch.) by HPLC-PDA-MS/MS and NMR spectroscopy. J Agric Food Chem 2003; 51 : 2896-2899

[60] Hvattum E. Determination of phenolic compounds in rose hip (Rosa canina) using liquid chromatography coupled to electrospray ionization tandem mass spectrometry and diode-array detection. Rapid Commun Mass Spectrom 2002; 16: 655-662

[61] Gosch C, Halbwirth H, Schneider B, Hölscher D, Stich K. Cloning and heterologous expression of glycosyltransferases from Malus $\mathrm{x}$ domestica and Pyrus communis, which convert phloretin to phloretin 2'-O-glucoside (phloridzin). Plant Sci 2010; 178: 299-306

[62] Schulze C, Bangert A, Kottra G, Geillinger KE, Schwanck B, Vollert H, Blaschek W, Daniel H. Inhibition of the intestinal sodium-coupled glucose transporter 1 (SGLT1) by extracts and polyphenols from apple reduces postprandial blood glucose levels in mice and humans. Mol Nutr Food Res 2014; 57: 1795-1808

[63] Day AJ, Gee JM, DuPont MS, Johnson IT, Williamson G. Absorption of quercetin-3-glucoside and quercetin-4-glucoside in the rat small intestine: the role of lactase phlorizin hydrolase and the sodium-dependent glucose transporter. Biochem Pharmacol 2003; 65: 1199-1206

[64] Day AJ, Canada FJ, Diaz JC, Kroon PA, McLauchlan R, Faulds CB, Plumb GW, Morgan MR, Williamson G. Dietary flavonoid and isoflavone glycosides are hydrolysed by the lactase site of lactase phlorizin hydrolase. FEBS Lett 2000; 468: 166-170

[65] Schwank B, Behrendt M, Naim HY, Blaschek W. Deglycosylation of individual flavonoids and flavonoid containing plant extracts by purified human intestinal lactase-phlorizin hydrolase (LPH). Planta Med 2011; 77: PA22

[66] Kwon O, Eck P, Chen S, Corpe CP, Lee J, Kruhlak M, Levine M. Inhibition of the intestinal glucose transporter GLUT2 by flavonoids. FASEB J 2007; 21: $366-377$

[67] Johnston KL, Clifford MN, Morgan LM. Possible role for apple juice phenolic compounds in the acute modification of glucose tolerance and gastrointestinal hormone secretion in humans. J Sci Food Agric 2002; 82: 1800-1805

[68] Shirosaki M, Koyama T, Yazawa K. Apple leaf extract as a potential candidate for suppressing postprandial elevation of the blood glucose level. J Nutr Sci Vitaminol 2012; 58: 63-67
[69] Powell DR, Smith M, Greer ], Harris A. LX4211 increases serum glucagonlike peptide 1 and peptide $Y Y$ levels by reducing sodium/glucose cotransporter 1 (SGLT1)-mediated absorption of intestinal glucose. J Pharmacol Exp Ther 2013; 345: 250-259

[70] Makarova E, Gornas P, Konrade I, Tirzite D, Cirule H, Pugajeva I, Seglina D, Dambrova M. Acute anti-hyperglycaemic effects of an unripe apple preparation containing phlorizin im healthy volunteers: a preliminary study. J Sci Food Agric 2015; 95: 560-568

[71] Sato S, Takeo J, Aoyama C, Kawahara H. $\mathrm{Na}^{+}$-glucose cotransporter (SGLT) inhibitory flavonoids from the roots of Sophora flavescens. Bioorg Med Chem 2007; 15: 3445-3449

[72] Yang J, Yang X, Wang C, Lin Q, Mei Z, Zhao P. Sodium-glucose-linked transporter 2 inhibitors from Sophora flavescens. Med Chem Res 2015; 24: $1265-1271$

[73] Goto T, Horita M, Nagai H, Nagatomo S, Nishida N, Matsuura Y, Nagaoka S. Tirliroside, a glycosidic flavonoid, inhibits carbohydrate digestion and glucose absorption in the gastrointestinal tract. Mol Nutr Food Res 2012; 56: 435-445

[74] Manach C, Williamson G, Morand C, Scalbert A, Remesy C. Bioavailability and bioefficacy of polyphenols in humans. I. Review of 97 bioavailability studies. Am J Clin Nutr 2005; 81: 230S-242S

[75] Walgren RA, Lin JT, Kinne RK, Walle T. Cellular uptake of dietary flavonoid quercetin 4 '- $\beta$-glucoside by sodium-dependent glucose transporter SGLT1. J Pharmacol Exp Ther 2000; 294: 837-843

[76] Wolffram S, Blöck M, Ader P. Quercetin-3-glucoside is transported by the glucose carrier SGLT1 across the brush border membrane of rat small intestine. J Nutr 2002; 132: 630-635

[77] Kottra G, Daniel H. Flavonoid glycosides are not transported by the human $\mathrm{Na}^{+} /$glucose transporter when expressed in Xenopus laevis oocytes, but effectively inhibit electrogenic glucose uptake. J Pharmacol Exp Ther 2007; 322: 829-835

[78] Ader P, Blöck M, Pietzsch S, Wolffram S. Interaction of quercetin glucosides with the intestinal sodium/glucose co-transporter (SGLT-1). Cancer Lett 2001; 162: 175-180

[79] Cermak R, Landgraf S, Wolffram S. Quercetin glucosides inhibit glucose uptake into brush-border-membrane vesicles of porcine jejunum. $\mathrm{Br}$ J Nutr 2004; 91: 849-955

[80] Schulze C, Bangert A, Schwanck B, Vollert H, Blaschek W, Daniel H. Extracts and flavonoids from onion inhibit the intestinal sodium-coupled glucose transporter 1 (SGLT1) in vitro but show no anti-hyperglycaemic effects in vivo in normoglycaemic mice and human volunteers. J Funct Foods 2015; 18: 117-128

[81] Snoussi C, Ducroc R, Hamdaoui MH, Dhaouadi K, Abaidi H, Cluzeaud F, Nazaret C, Le Gall M, Bado A. Green tea decoction improves glucose tolerance and reduces weight gain of rats fed normal and high-fat diet. J Nutr Biochem 2014; 25: 557-564

[82] Arai H, Hirasawa Y, Rahman A, Kusumawati I, Zaini NC, Sato S, Aoyama C, Takeo J, Morita H. Alstiphyllanines E-H, picraline and ajmaline-type alkaloids from Alstonia macrophylla inhibiting sodium glucose cotransporter. Bioorg Med Chem 2010; 18: 2152-2158 